\title{
Comparison of the oxidative stress response of two Antarctic fungi to different growth temperatures
}

\author{
Nedelina KOSTADINOVA ${ }^{1}$, Solveig TOSI ${ }^{2}$, Boryana SPASSOVA ${ }^{1}$ \\ and Maria ANGELOVA ${ }^{*}$ \\ ${ }^{1}$ The Stephan Angeloff Institute of Microbiology, Bulgarian Academy of Sciences, \\ Academician G. Bonchev 26, 1113 Sofia, Bulgaria \\ ${ }^{2}$ Department of Earth and Environmental Sciences, University of Pavia, \\ Via S. Epifanio 14, 27100, Pavia, Italy \\ *corresponding author <mariange@microbio.bas.bg>
}

\begin{abstract}
Two fungal strains, isolated from Livingston Island, Antarctica (Penicillium commune 161, psychrotolerant and Aspergillus glaucus 363, mesophilic) were investigated for a relationship between growth temperature and oxidative stress response. Cultivation at temperatures below $-\left(10\right.$ and $15^{\circ} \mathrm{C}$ and 10 and $20^{\circ} \mathrm{C}$ for P. commune and A. glaucus, respectively) and above $\left(25^{\circ} \mathrm{C}\right.$ and $30^{\circ} \mathrm{C}$ for $P$. commune and A. glaucus, respectively) the optimum caused significant difference in growth and glucose uptake in comparison with the control cultures. Enhanced level of reserve carbohydrates (glycogen and trehalose) was determined under cultivation at different temperatures from the optimal one. While the highest content of trehalose was found in the exponential phase, glycogen accumulation was observed in the stationary phase when growth conditions deteriorate. The growth at temperature below- and above-optimum caused strain-dependent changes in two antioxidant enzymes superoxide dismutase (SOD) and catalase (CAT). While SOD activity in the psychrotolerant strain increases with decreasing of growth temperature, the mesophilic A. glaucus demonstrated marked reduction of it at below- and above-optimal temperature. Decreasing trend of CAT activity was observed in both strains below the optimal temperature indicating a lack of antioxidant protection from this enzyme under the cold stress conditions.
\end{abstract}

Key words: Antarctic, Livingston Island, fungi, physiological cell response, trehalose, glycogen, antioxidant enzymes.

\section{Introduction}

The climate of Antarctic is the coldest and driest known on Earth. The incredibly harsh environment characterized by low temperature, low water availability, frequent freeze-thaw cycles, strong winds, ultraviolet radiation etc., precludes most of the life forms. As a result, the biology of Antarctica, more 
than in other continents, is dominated by micro-organisms, with a high level of adaptation and able to withstand severe environmental conditions (Ruisi et al. 2007; Onofri et al. 2015). The Antarctic micro-organisms capable of growing at low temperatures are referred as psychrophiles and psychrotrophes (also called psychrotolerants) (Russell, 2006; Margesin et al. 2009). Psychrophiles grow at or below $0^{\circ} \mathrm{C}$ and have an optimum growth temperature at $15^{\circ} \mathrm{C}$ and an upper limit of $\leq 20^{\circ} \mathrm{C}$. In contrast, psychrotolerants, which can also grow close to zero, have optima and upper limits above these temperatures and may well grow at mesophilic temperatures with optima above $30^{\circ} \mathrm{C}$; hence they could be considered as being cold-tolerant mesophiles (Russell 2006; Gonçalves et al. 2013).

Microscopic fungi are an important part of the polar ecosystem because they mineralize nutrients from soil organic matter and participate in symbiotic associations such as mycorrhiza and lichens (Newsham et al. 2009; Park et al. 2015; Zhang et al. 2015). Moreover, the ecological impact of pathogenic fungi has been reported (Gonçalves et al. 2012; Wang et al. 2015; Matsumoto and Hsiang 2016). Despite the low number of habitats available for microbial life in the Antarctic continent, a significant number of different fungal species, including new taxa have been isolated and described (see Selbman et al. 2014). The major portion of them (99.4\%) belongs to phyla of Chytridiomycota, Zygomycota, Ascomycota and Basidiomycota (Onofri et al. 2005). The new sequencing technologies helped to elucidate the fungal diversity in Antarctica through identifying uncultivable isolates. The molecular methods confirmed domination of Ascomycota and Basidiomycota, especially in Dry Valley soils (Arenz et al. 2006; Cantrell et al. 2011; Dreesens et al. 2014; Cox et al. 2016). The analysis of environmental DNA and RNA (cDNA) for inland Dry Valleys soil showed that approximately half of fungal phylotypes recovered from the RNA-derived library did not affiliate phylogenetically with any known fungus (Rao et al. 2012).

During the last years many investigations have been carried out about the floristic, ecophysiological, molecular and, most recently, phylogenetic aspects of Antarctic fungi (Onofri et al. 2008). A big deal of results has focussed mainly on the adaptations of protein (enzyme) activity, protein synthesis and membrane lipids (Feller et al. 2006; Fenice et al. 2012). On the contrary, little is known about their physiological mechanisms responsible for growth and survival at low temperature. Cold-stress response includes synthesis of melanin-like pigments, formation of highly melanized or sterile hyphae, meristematic and flexible morphology (Ruisi et al. 2007; Nonzom and Sumbali 2014). Furthermore, there have been reports about changes in fatty acid composition, accumulation of cryoprotective carbohydrates, synthesis of exopolysaccharides, dehydratation ability etc. (Ruisi et al. 2007; Silvi et al. 2013).

On the other hand, the relationship between low temperature and oxidative stress events as well as the participation of antioxidant defence in cold-stress response has been widely studied in bacteria and plants, but little attention has 
been paid to fungi. Cold environment induces enhanced generation of reactive oxygen species (ROS) in all aerobic cells, such as superoxide anion radical $\left(\mathrm{O}_{2}^{-}\right)$, hydrogen peroxide $\left(\mathrm{H}_{2} \mathrm{O}_{2}\right)$, singlet $\mathrm{O}_{2}$, and the highly reactive hydroxyl radicals ( $\mathrm{OH}$ ) (see Sharma et al. 2012). These strong oxidants are highly reactive towards all biomolecules (DNA, protein, and lipids), and severely harmful for cell survival. As a result, oxidative stress occurs due to the imbalance between oxidants and antioxidants, in favor of the oxidants. To scavenge ROS and prevent damage, all aerobic cells have evolved a complex defence system consisting of both enzymatic and non-enzymatic antioxidants. The main antioxidant enzymes are superoxide dismutase (SOD), catalase (CAT), and glutathione peroxidases (GPX). SOD are a group of metalloenzymes that catalyse the dismutation of $\left(\mathrm{O}_{2}^{-}\right)$to hydrogen peroxide and $\mathrm{O}_{2}$. The $\mathrm{H}_{2} \mathrm{O}_{2}$ resulted from this reaction is subsequently converted to $\mathrm{H}_{2} \mathrm{O}$ and $\mathrm{O}_{2}$ by CAT or GPX (Fridovich 1998; Nimse and Pal 2015). Furthermore, comparison between survival strategies of different thermal classes of micro-organisms (psychrophiles, psychrotolerant and mesophiles) isolated from permanently cold habitats could provide much insight into the adaptations to life in the cold. One hypothesis suggests that responses of Antarctic fungi to different stresses appear similar to those found even in temperate regions (Ruisi et al. 2007).

Previously Gocheva et al. (2006; 2009) showed the relationship between low temperatures and oxidative stress events in fungal strains isolated from soil samples of different regions of Antarctica: Casey Station, Terra Nova Bay and South Georgia. Also, Kostadinova et al. (2009) have isolated fungal strains from permanent Bulgarian Antarctic base "St. Kl. Ohridski" on Livingston Island in the South Shetland Islands (Maritime Antarctica). The short-term treatment with cold temperature induced transient oxidative stress in two Antarctic fungi of different thermal classes, the psychrotolerant Penicillium commune 161 and mesophilic Aspergillus glaucus 363 (Kostadinova et al. 2012). In this study, both strains were tested for the effect of growth temperature on a range of physiological parameters, including growth, glucose consumption and accumulation of reserve carbohydrates. The report demonstrates also the role of antioxidant enzymes superoxide dismutase (SOD) and catalase (CAT). The experiments were designed to obtain information whether there exists any difference in cell response of the psychrotolerant and the mesophilic strain.

\section{Materials and methods}

Fungal strains, culture media and cultivation. - The fungal strains, P. commune 161 and A. glaucus 363, were isolated from soil samples collected in Livingston Island in the South Shetland Islands (Maritime Antarctica) during the Bulgarian Antarctic expedition 2006/07 and were included in the experiments. 
They were isolated at temperature 4 and $25^{\circ} \mathrm{C}$ for $P$. commune and A. glaucus, respectively. The strains belong to the Mycological Collection of the Stephan Angeloff Institute of Microbiology, Sofia, and they are maintained at $4^{\circ} \mathrm{C}$ on Beer agar, pH 6.3.

For the purpose of temperature characteristic, both Antarctic strains were cultivated individually in plates of $9 \mathrm{~cm}$ of diameter with the Beer agar medium (Fassatiová 1986). Triplicates of each plate were incubated in the dark at 0, 4, $10,12,18,20,25,30$ and $35^{\circ} \mathrm{C}$ for 3 weeks. The diameter of the colony was measured every 3 days.

The composition of the seed and production media was as described previously (Angelova et al. 1995). Cultivation was performed in 3 L bioreactors, ABR-09, equipped with $\mathrm{pH}$ and automatic dissolved oxygen (DO) monitoring equipment and a control system. For the inoculum, $80 \mathrm{ml}$ of seed medium was inoculated with $10^{7}$ spores in $500 \mathrm{ml}$ Erlenmeyer flasks. The cultivation was performed on a shaker $(220 \mathrm{rpm})$ for $24 \mathrm{~h}$ at $20^{\circ} \mathrm{C}$ and $25^{\circ} \mathrm{C}$ for $P$. commune 161 and A. glaucus 363 , respectively. For bioreactor cultures, $200 \mathrm{ml}$ of the seed culture was brought into the $3 \mathrm{~L}$ bioreactor, containing $1800 \mathrm{ml}$ of the productive medium. The cultures were grown for $120 \mathrm{~h}$ with a stirred speed of $400 \mathrm{rpm}$ air flow, 1 v.v.m. at $10,15,20$ and $25^{\circ} \mathrm{C}$ for P. commune 161 and $10,20,25$ and $30^{\circ} \mathrm{C}$ for A. glaucus 363 . In all the experiments the control is represented by culture at the optimal temperature.

Cell-free extract preparation and antioxidant enzyme activity determination. - The cell-free extract was prepared as described earlier (Angelova et al. 1995). SOD activity was measured by the nitro-blue tetrazolium (NBT) reduction method of Beauchamp and Fridovich (1971). One unit of SOD activity was defined as the amount of enzyme protein required for inhibition of the reduction of NBT by 50\% $\left(\mathrm{A}_{560}\right)$ and was expressed as units per mg protein $(\mathrm{U} / \mathrm{mg}$ protein). Catalase activity was determined by monitoring the decomposition of $18 \mathrm{mM} \mathrm{H}_{2} \mathrm{O}_{2}$ at $240 \mathrm{~nm}$ (Beers and Sizer 1952). One unit of activity is that which decomposes $1 \mu \mathrm{mol}$ of $\mathrm{H}_{2} \mathrm{O}_{2} \mathrm{~min}^{-1} \mathrm{mg}$ protein ${ }^{-1}$ at $25^{\circ} \mathrm{C}$ and $\mathrm{pH}$ 7.0. Specific activity is given as $\mathrm{U} / \mathrm{mg}$ protein.

Other analytical methods. - Glycogen and trehalose contents were determined following the procedure described by Parrou et al. (1997). Soluble reducing sugars were determined by the Somogy-Nelson method (Somogy 1952). Protein was estimated by the Lowry procedure (Lowry et al. 1951) using bovine serum albumin as standard. The determination of biomass dry weight was performed on samples of mycelia harvested throughout the culture period. The culture fluid was filtered through a Whatman (Clifton, USA) No 4 filter. The separated mycelia were washed twice with distilled water and dried to a constant weight at $105^{\circ} \mathrm{C}$. 
Other analytical methods. - The results obtained in this investigation were evaluated from at least three repeated experiments using three parallel runs. The statistical comparison between controls and treated cultures was determined by the Student's $t$-test for MIE (mean interval estimation) and by one-away analysis of variance (ANOVA) followed by Dunnet's post test, with a significance level of 0.05 .

\section{Results}

\section{Effect of temperature on growth and glucose consumption of Antarctic} fungal strains. - The effect of temperature on maximum colony growth of $P$. commune 161 and A. glaucus 363 is shown in Fig. 1. Presented data demonstrated a big difference in the growth characteristics between both Antarctic strains. Temperature response experiments revealed that $P$. commune 161 was capable of growth on agar medium within a temperature range of $0-25^{\circ} \mathrm{C}$, with an optimum at of $15-20^{\circ} \mathrm{C}$. A. glaucus 363 grew and formed colonies at temperatures between $12-35^{\circ} \mathrm{C}$, while the optimum of temperature for growth was $25-30^{\circ} \mathrm{C}$. According to the temperature range for growth and optimum, they could be classified as psychrotolerant (P. commune 161) and mesophilic (A. glaucus 363), respectively.

The temperature profiles of the model strains cultivated under submerged conditions are shown in Fig. 2. Both strains demonstrated growth under all temperature tested with the exception of the mesophilic strain A. glaucus at $10^{\circ} \mathrm{C}$. Under the optimal temperature conditions, the psychrotolerant strain accumulated

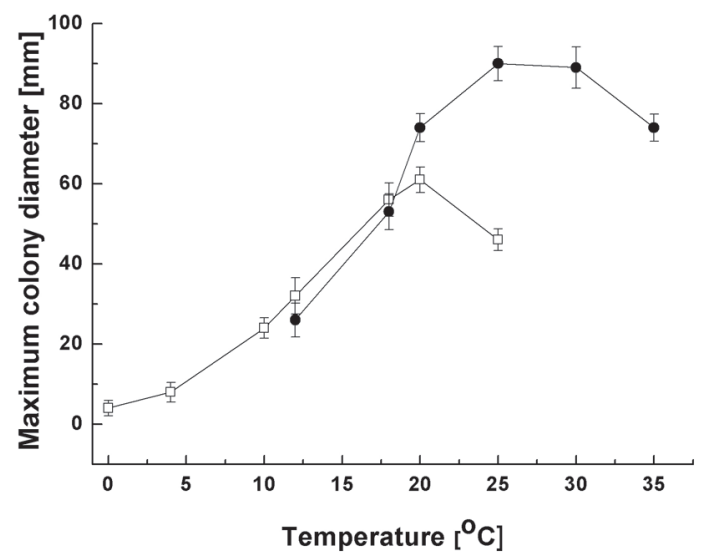

Fig. 1. Mean maximum colony diameter (cm) of P. commune $161(\square)$ and A. glaucus $363(\bullet)$ grown at different temperature regimes $\left(0-35^{\circ} \mathrm{C}\right)$. 

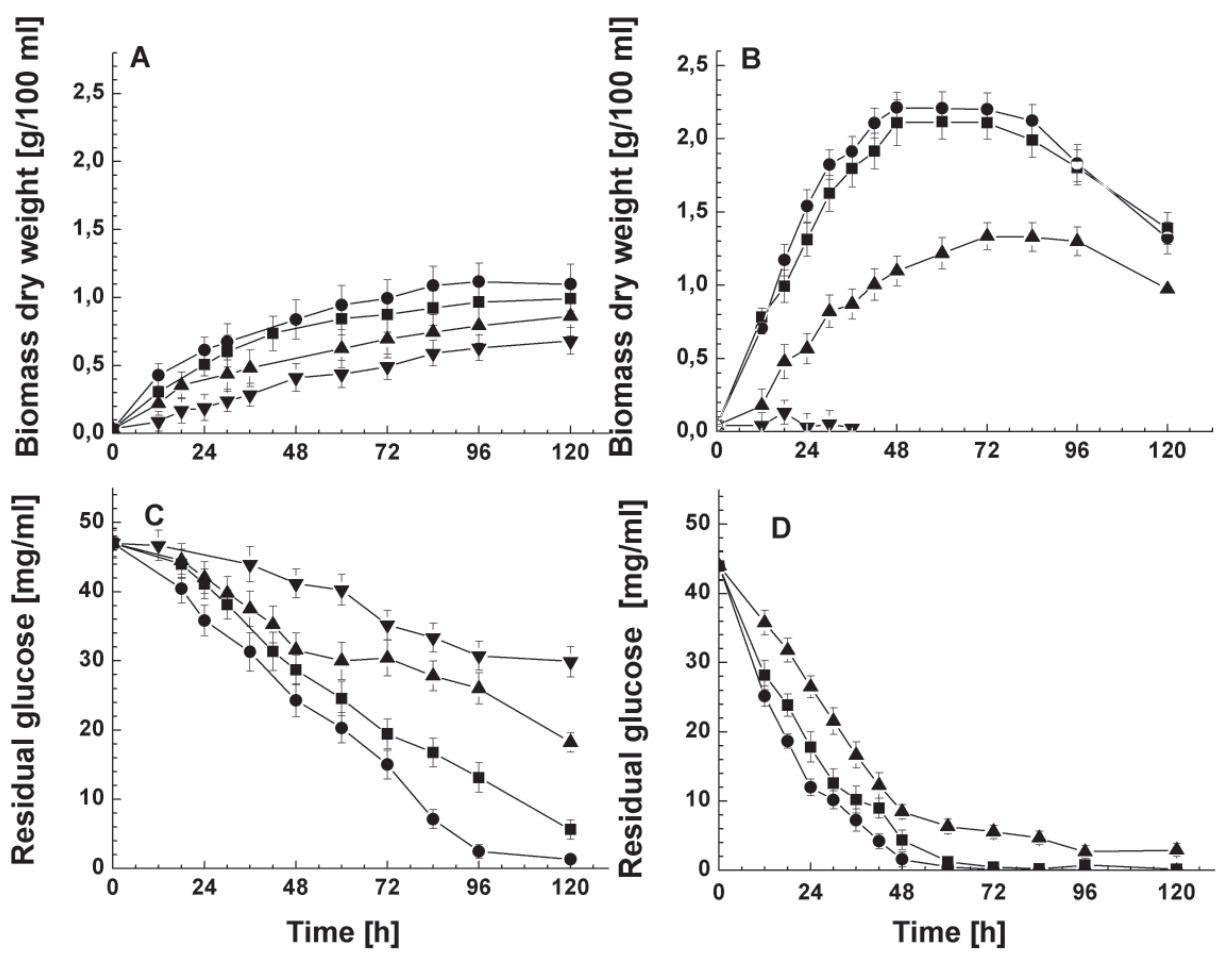

Fig. 2. Biomass (A, B) and glucose (C, D) levels in P. commune 161 (A, C) and A. glaucus 363 $(\mathrm{B}, \mathrm{D})$ under different temperatures: for P. commune $161-(\boldsymbol{\bullet})-25^{\circ} \mathrm{C},(\bullet)-20^{\circ} \mathrm{C},(\boldsymbol{\Delta})-15^{\circ} \mathrm{C}$, $(\boldsymbol{\nabla})-10^{\circ} \mathrm{C}$; for A. glaucus $363-(\boldsymbol{\bullet})-30^{\circ} \mathrm{C},(\bullet)-25^{\circ} \mathrm{C},(\boldsymbol{\Delta})-20^{\circ} \mathrm{C},(\boldsymbol{\nabla})-10^{\circ} \mathrm{C}$. Bars represent $\mathrm{SD}$ of means. The effect of treatment was significant for the temperature treatment $(\mathrm{P} \leq 0.05)$.

about 2-fold less biomass (Fig. 2A) than the mesophilic fungus (Fig. 2B). The difference was statistically significant $(\mathrm{p} \leq 0.05)$. While the strain $P$. commune 161 exhibited a good development even at $10^{\circ} \mathrm{C}$, mesophilic strain A. glaucus 363 showed very fast accumulation of biomass at 25 and $30^{\circ} \mathrm{C}$.

Figure 2 also illustrates typical growth curves (exponential growth, stationary phase and decline phase) at all temperatures used for mesophilic strain in shaken liquid cultures. It should be added that upon incubation at lowest temperatures, the time until stationary phase was reached later than under the other temperature conditions and maxima of fungal growth decreased. In contrast, the curves of the psychrotolerant strain outlined continuous (albeit slight) growth until the end of cultivation. Onset of a stationary phase was observed at optimal temperature $\left(20^{\circ} \mathrm{C}\right)$ only after 96 hour.

The concentration of glucose in the culture medium was measured throughout the experiment (Fig. 2). Maximum glucose consumption occurred in cultures incubated at optimal growth temperature compared to the lower temperatures. 
A comparison of the model strains shows also that the consumption of glucose by mesophilic strain (Fig. 2D) was faster than that of psychrotolerant fungus (Fig. 2C). While the culture of A. glaucus 363 consumed about 90-99\% in all variants after 72 hour, $P$. commune 161 achieved $98 \%$ only at optimum temperature at the end of cultivation. Moreover, the influence of temperature variation on the glucose decay was more sensitive for the psychrotolerant strain. Comparing the curves in the Fig. $2 \mathrm{C}$, it was possible to verify that the downshift of temperature from 20 to $10^{\circ} \mathrm{C}$ caused significant decrease in glucose consumption. It is noteworthy that the temperature above optimum $\left(25\right.$ and $30^{\circ} \mathrm{C}$ for $P$. commune 161 and A. glaucus 363, respectively) resulted in reduction of glucose uptake compared to the control.

Temperature-dependent accumulation of reserve carbohydrates. - As shown in Fig. 3, reserve carbohydrates were detected in both Antarctic strains upon exposure to all the tested temperatures. In the control cultures (at optimal temperature), no significant increase in the level of either carbohydrate was observed during cultivation. A similar trend was observed in the psychrotolerant
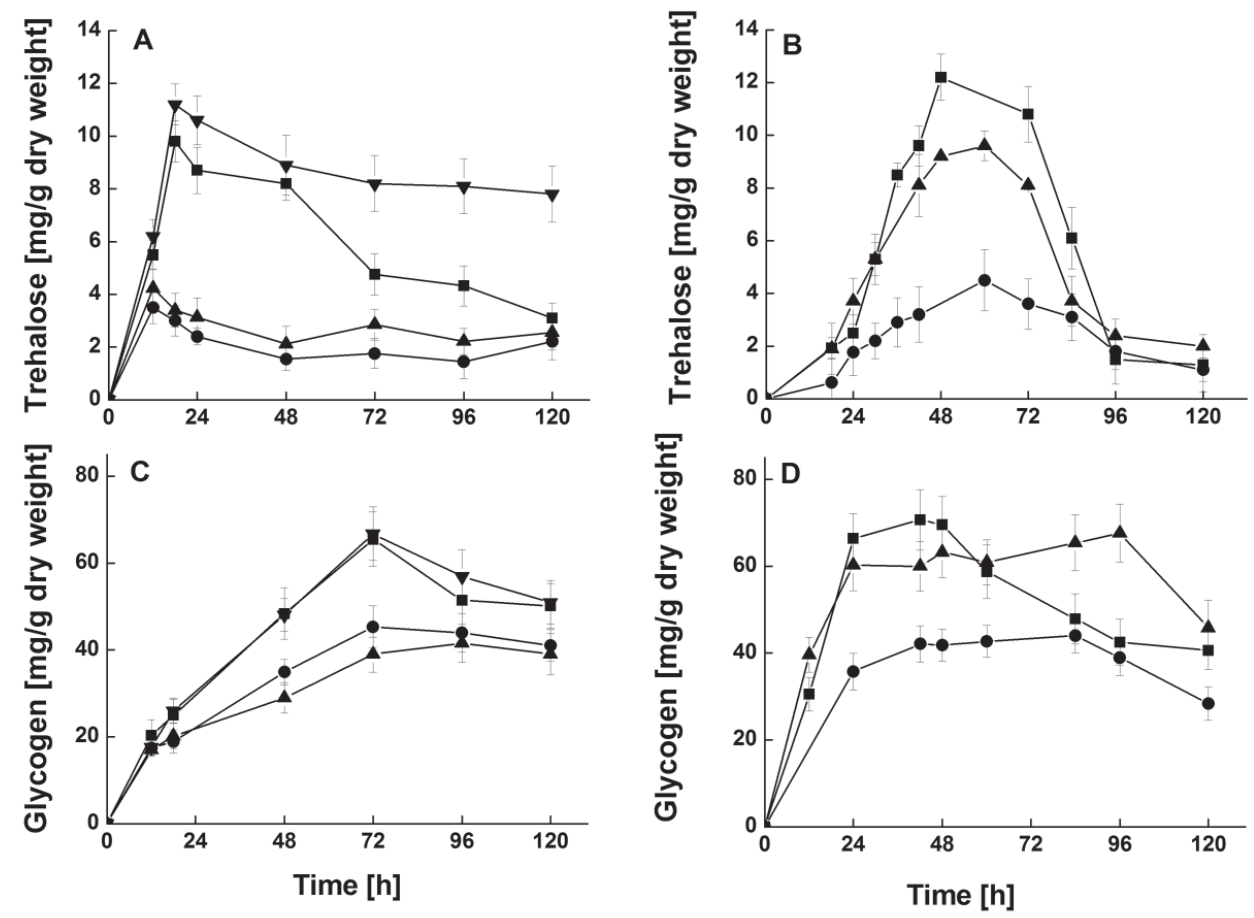

Fig. 3. Trehalose (A, B) and glycogen (C, D) levels in P. commune 161 (A, C) and A. glaucus 363 (B, D) under different temperatures: for $P$. commune $161-(\bullet)-25^{\circ} \mathrm{C},(\bullet)-20^{\circ} \mathrm{C},(\boldsymbol{\Delta})-15^{\circ} \mathrm{C}$, ( $)-10^{\circ} \mathrm{C}$; for A. glaucus $363-(\boldsymbol{\bullet})-30^{\circ} \mathrm{C},(\bullet)-25^{\circ} \mathrm{C},(\boldsymbol{\Delta})-20^{\circ} \mathrm{C}$. Bars represent SD of means. The effect of treatment was significant for the temperature treatment $(\mathrm{P} \leq 0.05)$. 
strain P. commune 161 , grown at $15^{\circ} \mathrm{C}$ (near to the optimum) (Fig. 3A, 3C), but the maximum level of trehalose and glycogen was about $30 \%$ higher than that in the control variants. Each significant change in growth temperature below or above optimum resulted in enhanced content of reserve carbohydrates. The maximum level assessment showed that $P$. commune cells accumulated 4,7- and 4-fold more trehalose and 2-fold more glycogen when cultivated at temperature of $10^{\circ} \mathrm{C}$ (below optimum) and $25^{\circ} \mathrm{C}$ (above optimum), respectively, compared with control culture.

Our results indicated that the accumulation of both reserve carbohydrates in the mesophilic strain A. glaucus 363 cultivated under above- and belowoptimal temperatures (Fig. 3B, 3D) resembled that of the psychrotolerant strain (Fig. 3A, 3C). Furthermore, the highest trehalose content is coincided with the late exponential and early stationary growth phase while the highest glycogen concentrations were found from the exponential phase until the late stationary phase.

Antioxidant enzyme activities at different growth temperature. - To find out whether the growth of Antarctic strains at above- and below-optimal was associated with antioxidant enzyme defence, we determined changes in activities of SOD and CAT (Fig. 4). The SOD activity in cell homogenate from the psychrotolerant strain $P$. commune 161 increased with decreasing growth temperatures (Fig. 4A). Our data demonstrated 2.2- and 1.5-fold higher maximal SOD level in cultures, grown at 10 and $15^{\circ} \mathrm{C}$, respectively compared to the control. On the other hand, cultivation at $25^{\circ} \mathrm{C}$ led to insignificant enhancement of the enzyme activity compared to the control variant. The examinations during the growth cycle at optimal temperature indicated an increase during exponential growth phase, and become constant during the stationary phase. Under conditions of low temperature treatment, the time courses of SOD production show two maxima: at 60 hour (when P. commune is still growing) and 96 hour (in early stationary phase).

In marked contrast, SOD activity decreased in cells of mesophilic strain A. glaucus 363 grown at temperatures different from optimal $25^{\circ} \mathrm{C}$ (Fig. 4B). Cultivation at $20^{\circ} \mathrm{C}$ led to 2 -fold reduction in enzyme level, whereas enhanced growth temperature $\left(30^{\circ} \mathrm{C}\right)$ caused in activity. Maximum enzyme activity at optimal temperature was measured at 24 hour, (in the active fungal growth), followed by a continuous decline up to 60 hour and a second maximum, which was reached at the end of stationary phase ( 84 hour). Decrease in the temperature $\left(20^{\circ} \mathrm{C}\right)$ caused a delay in reaching of maximum activity.

It is of interest to note that the cultivation of psychrotolerant strain at temperature below optimal lead to opposite cell response concerning CAT activity. As shown in Fig. $4 \mathrm{C}$, temperatures of 15 and $10^{\circ} \mathrm{C}$ lead to a sharp decrease in enzyme level in comparison to the control. In the experiment with the mesophilic 

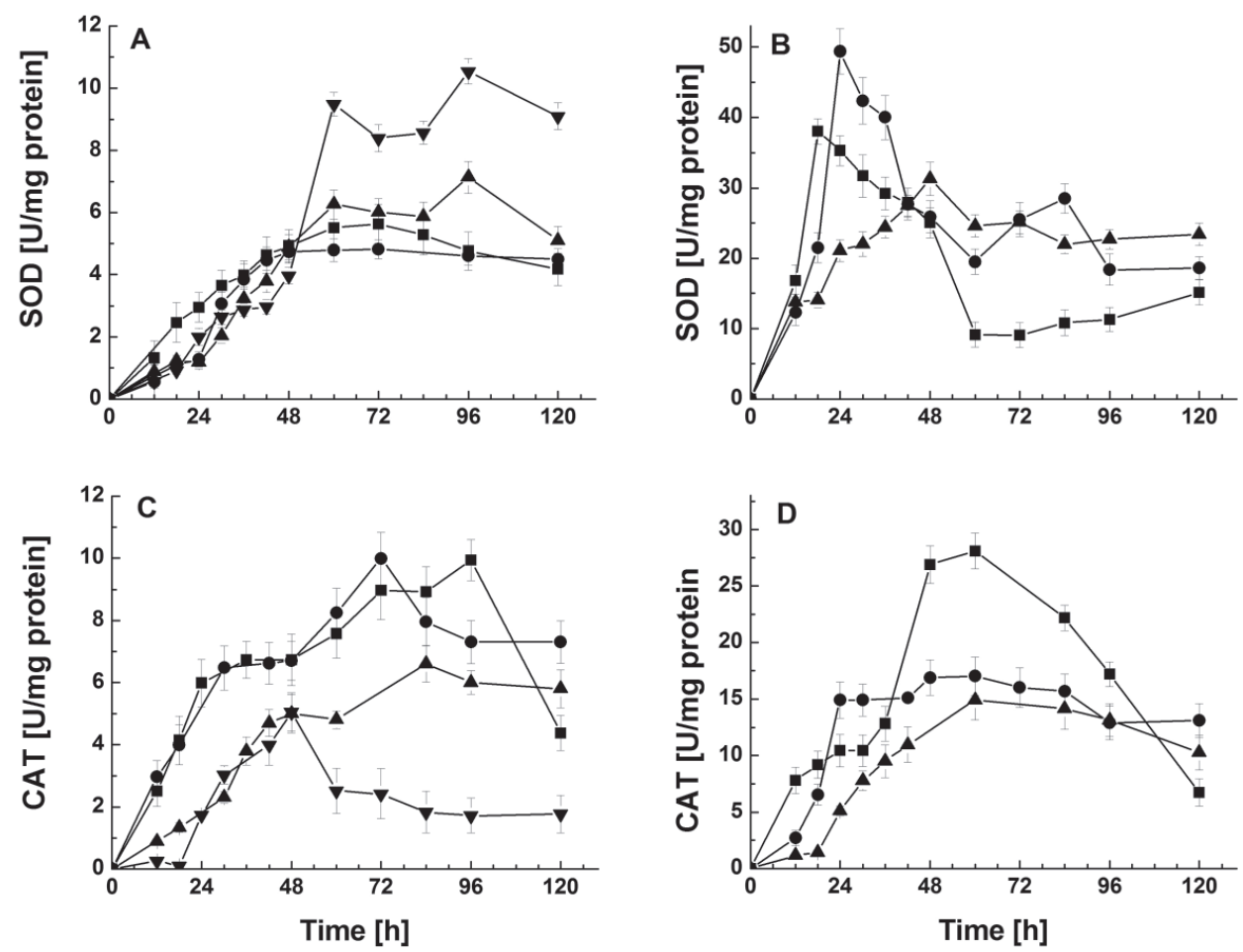

Fig. 4. SOD (A, B) and CAT (C, D) activities in cultures of P. commune 161 (A, C) and A. glaucus 363 (B, D), cultivated at different temperatures. The treatment of the mycelia was carried out as described in the legend to Fig. 3. Bars represent SD of means. The effect of treatment was significant for the temperature treatment $(\mathrm{P} \leq 0.05)$.

strain a similar trend was observed (Fig. 4D). The maintenance of temperature above the optimal for the growth of A. glaucus caused a significant increase in CAT activity (Fig. 4D), while P. commune did not demonstrate any alterations compared to the control (Fig. 4C).

\section{Discussion}

Despite the fact that so much of our planet is cold, majority of cold-adapted micro-organisms are mesophilic or psychrotolerant (psychrotrophic) rather than psychrophilic (Russell 2006). Our Antarctic strain P. commune 161, which was isolated at temperature $4^{\circ} \mathrm{C}$, can grow well in the range of temperature between 4 and $25^{\circ} \mathrm{C}$ and has an optimum at $20^{\circ} \mathrm{C}$. According to the recognized definition, this strain is not a true psychrophilic species as it can grow at $25^{\circ} \mathrm{C}$. Recently, the terms stenopsychrophile and eurypsychrophile have been favoured for the cold-adapted micro-organisms (psychrophilic and psychrotolerant, respectively) 
(Wang et al. 2015). Thus, the growth data of $P$. commune 161 specify this strain as psychrotolerant or eurypsychrophile. The search for psychrophilic filamentous fungi in Antarctica has been successful in very rare cases (Margesin 2009). In contrast, there appeared many reports on the isolation of psychrotolerant fungal strains (Frisvad 2008). Gonçalves et al. (2013) reported on a mesophilic, psychrotolerant fungus Penicillium solitum inhabiting marine sediments of Antarctica. The fungus Lecanicillium muscarium CCFEE 5003, isolated from continental Antarctica has been characterized as a strain with psychrotolerant behavior (Fenice 2016).

At the same time, the colony growth and growth kinetic data indicate that A. glaucus 363 is a mesophilic strain since it exhibited optimal growth temperatures around $25^{\circ} \mathrm{C}$ and was unable to grow at $10^{\circ} \mathrm{C}$. As known, Antarctic mycoflora contains also fungi, which are represented by mesophilic species, present as viable propagules but unable to reproduce except in rarely favourable climatic conditions (Ruisi et al. 2007). Other species, able to grow actively, at least under Antarctic summer conditions, comprise particular ecotypes of cosmopolitan species showing mesophilic behaviour as an adaptation to the cold Antarctic climate (Onofri et al. 2005).

It should be noted that the psychrotolerant strain $P$. commune 161 demonstrated lower biomass productivity than the mesophilic A. glaucus 363 at optimal temperature. Presumably, cold-adapted micro-organisms have to synthesize a wide range of compounds essential for survival at low temperature, such as reserve carbohydrates, exopolysaccharides, polyoles, melanines etc. (Sterflinger 2006). The high metabolic cost for synthesizing all these compounds significantly affects growth velocity of fungi which show a very slow growth rate (Selbman et al. 2014). In addition, they have to cope with ROS and oxidative damages in cells.

Glucose uptake illustrated clear dependence on temperature and thermal characteristics of the strains. We detected significant reduction in the glucose consumption in $P$. commune compared to A. glaucus. These data can be seen as a confirmation of above mentioned suggestion about differences in biomass production between both strains, psychrotolerant and mesophilic. Temperature downshift also resulted in considerable decrease in glucose utilization. Psychrotolerant and mesophilic strain grown at 10 and $20^{\circ} \mathrm{C}$, respectively, take up glucose much more slowly. Under temperature induced oxidative stress, fungi reduce the glucose and ammonia uptake (Li et al. 2008). In this way, the low temperature-induced stress can cause a dynamic rearrangement of the metabolic flux to the pentose phosphate pathway leading to the generation of the reduced electron carrier NADPH (Dos Reis et al. 2013). Fungal cells accelerated the production of glucose by gluconeogenesis and the production of amino acids important to compose the repertoire of molecules to the oxidative stress response (Dos Reis et al.2013). Kostadinova et al. (2011) showed a re-routing of carbon metabolism away from glycolysis into the pentose phosphate pathway which serves as a cellular stress-resistance mechanism under cold stress conditions. 
Data published in the literature on the effect of low temperatures on glucose uptake have shown contradictory results. Fukunaga \& Russell (1990) reported that the glucose uptake in a psychrotrophic Pseudomonas spp., isolated from Antarctica was maximal at $20^{\circ} \mathrm{C}$ but fell at lower temperatures. For two yeast strains belonging to the species Rhodotorula aurantiaca, half-saturation constant for glucose uptake for glucose $(K s)$ was relatively constant below optimal temperatures $\left(10^{\circ} \mathrm{C}\right.$ and $17^{\circ} \mathrm{C}$ for the psychrophilic and psychrotolerant strain, respectively) but rose when the temperature increased beyond the optimum (Sabri et al. 2000). The ability of cold-adapted micro-organisms to grow slowly at low temperatures may actually be an advantage in nutrient-poor environments, where a rapid exhaustion of available resources would lead to starvation (Russell 2006). In contrast, glucose uptake in a psychrotrophic bacterial strain from permanently-cold Antarctic environment was maximal at $0^{\circ} \mathrm{C}$ and decreased up to $15-20^{\circ} \mathrm{C}$ (Ellis-Evans and WynnWilliams 1985).

Production of reserve carbohydrates by stressed cells appears to be a critical adaptation that protects micro-organisms against a wide variety of potentially lethal conditions (Feofilova et al. 2000; Kanwal et al. 2011). Growth and survival strategies by cold-adapted fungi also included accumulation of trehalose and glycogen in the cells (Ruisi et al. 2007; Frisvad 2008; Gocheva et al. 2009). We demonstrate here that trehalose and glycogen accumulate in both Antarctic cultures during cold shock (i.e., $10^{\circ} \mathrm{C}$ for psychrotolerant strain and $20^{\circ} \mathrm{C}$ for mesophilic strain). It is noteworthy that a similar induction of trehalose and glycogen was observed at temperatures above the optimum. An accumulation of cryoprotective carbohydrates in response to suboptimal growth temperature was observed in Humicola marvinii and Mortierella elongata, described from fell-field soils in maritime Antarctica (Weinstein et al. 2000) and in yeast strains (Schade et al. 2004).

The mechanism by which reserve carbohydrates protects against cold stress still remains unknown. According to Da Costa Morato Nery et al. (2008) this mechanism is involved in minimizing the oxidative damage caused to both proteins and lipids, which would require the presence of trehalose on both sides of the lipid bilayer. There are data for up-regulation of the genes, responsible for trehalose- and glycogen-metabolizing enzymes, resulting in their accumulation under conditions of cold stress (Aguilera et al. 2007; Kostadinova et al. 2009; Iordachescu and Imai 2011). Interestingly, Tsuji (2016) reported that two strains of the Antarctic Mrakia blollopis demonstrate difference in cold stress response. $M$. blollopis $\mathrm{SK}-4$, which grew well under subzero temperatures, accumulated high levels of TCA-cycle metabolites, lactic acid, aromatic amino acids and polyamines. At the same time, in M. blollopis TKG1-2, which did not grow efficiently, cold stress strongly induced the metabolites of the TCA cycle, but other metabolites were not highly accumulated in the cell.

Cell response against oxidative stress includes increase in the activities of SOD and CAT which are key enzymes for directly scavenge ROS (Zhang et al. 
2003, Gocheva et al. 2009; Sharma et al. 2012). There are only very few reports in published literature about effect of low growth temperature on antioxidant enzyme defense. Chu et al. (2016) demonstrated higher activities in SOD, CAT, and APX in arbuscular mycorrhizal fungi under cold-stress conditions. Antioxidants could decrease the accumulation of ROS and reduce the oxidative damage in cells under cold stress. For example, temperature downshift induces antioxidant response in Saccharomyces cerevisiae (Zhang et al. 2003). Gocheva et al. (2006) also showed that the growth at below-optimal temperature was accompanied by typical oxidative stress reaction - an enhanced expression of both antioxidant enzymes. Interestingly, in the present study, a different response was established. Moreover, strain-dependent changes in SOD activity were observed. While SOD activity in the psychrotolerant strain increases with decreasing growth temperature, the mesophilic A. glaucus demonstrated marked reduction below and above optimal temperature. Similar decreasing trend was observed for CAT activity in both strains. An increase in SOD activity with a decrease in CAT activity has been reported in plants subjected to abiotic stress (see Lu et al. 2008). The differential response of antioxidative enzymes to cold stress in P. commune and A. glaucus may be attributed to varied level of ROS generation in strains belonging to different thermal classes. The depression in SOD activity in the cold-stressed cells of the mesophilic strain may be a consequence of decreased de novo synthesis of SOD proteins or irreversible inactivation of enzyme proteins from increased ROS production resulting from cold-stress metabolism. This situation may be a result of significant increase in the rate of $\mathrm{O}_{2}$ - formation and subsequently $\mathrm{H}_{2} \mathrm{O}_{2}$ accumulation throughout the cold stress. At the same time, excess production of ROS can inactivate CAT activity at higher concentrations, probably by inactivating the enzyme-bound heme group (Willekens et al. 1997). Probably, the decrease of catalase activity could be compensated by the up-regulation of peroxidases (Sofo et al. 2015).

Moreover, the time courses of SOD production showed two maxima at 10 and $15^{\circ} \mathrm{C}$ for the P. commune and at $25^{\circ} \mathrm{C}$ for A. glaucus. A similar phenomenon, a secondary increase in SOD activity during the late stationary phase, has been observed for SOD production by filamentous fungi and yeasts (Shilova et al. 1989; Angelova et al. 1996). It can be explained by an intensification of the process of $\mathrm{O}_{2}{ }^{-}$generation when the cells utilize endogenous sources of carbon and nitrogen (organic or amino acids).

Taken together, the present results showed that although the both tested strains were isolated from Antarctic soil samples, cold treatment caused significant differences in physiological cell response depending on their thermal characteristics regarding:

- growth and glucose uptake. The psychrotolerant strain $P$. commune demonstrated growth and glucose uptake retardation compared to the mesophilic strain A. glaucus 
- $\quad$ articipation of the first antioxidant enzyme, SOD in cold survival. While the psychrotolerant strain showed lower basal level of SOD activity that increases with decreasing growth temperature, the higher basal SOD activity in the mesophilic strain demonstrated marked reduction at below and above optimal temperature.

At the same time, both the psychrotolerant and mesophilic strain accumulated glycogen and trehalose at temperature different from the optimum. The results suggested also a lack of antioxidant protection from CAT.

Acknowledgement. - This work was supported by the Bulgarian Scientific Fund (grants VU-B-205 and DO02-172), which is greatly acknowledged.

\section{References}

Aguilera J., RAndeZ-Gil F. and PRIETo J.A. 2007. Cold response in Saccharomyces cerevisiae: new functions for old mechanisms. FEMS Microbiology Reviews 31: 327-341.

Angelova M., Genova L., Pashova S., Slokoska L. and DolashKa P. 1996. Effect of cultural conditions on the synthesis of superoxide dismutase by Humicola lutea 110. Journal of Fermentation and Bioengineering 82: 464-468.

Angelova M., GenOVa L., SlokosKa L. and PAshova S. 1995. Effect of glucose on the superoxide dismutase production in fungal strain Humicola lutea. Canadian Journal of Microbiology 41: 978-983.

Arenz B.E., Held B.W., Jurgens J.A., Farrell R.L. and Blanchette R.A. 2006. Fungal diversity in soils and historic wood from the Ross Sea region of Antarctica. Soil Biology and Biochemistry 38: 3057-3064.

BEAUCHAMP C. and FRIDOVICH I. 1971. Superoxide dismutase: improved assays and an assay applicable to acrylamide gels. Analytical Biochemistry 44: 276-287.

BEERS R.F. and SIZER I.W. 1952. A spectrophotometric method for measuring the breakdown of hydrogene peroxide by catalase. The Journal of Biological Chemistry 195: 133-140.

CANTREll S.A., DiAnese J.C., Fell J., Gunde-Cimerman N. and ZALAR P. 2011. Unusual fungal niches. Mycologia 103: 1161-1174.

Chu X.T., Fu J.J., Sun Y.F., XU Y.M., Miao Y.J., XU Y.F., Hu T.M. 2016. Effect of arbuscular mycorrhizal fungi inoculation on cold stress-induced oxidative damage in leaves of Elymus nutans Griseb. South African Journal of Botany 104: 21-29.

Cox F., Newsham K.K., Bol R., Dungait J.A.J. and Robinson C.H. 2016. Not poles apart: Antarctic soil fungal communities show similarities to those of the distant Arctic. Ecology Letters 19: 528-536.

Da Costa Morato Nery D., Da Silva C.G., Mariani D., Fernandes P.N., Pereira M.D., PANEK A.D. and ElEUTHERIO E.C.A. 2008. The role of trehalose and its transporter in protection against reactive oxygen species. Biochimica et Biophysica Acta 1780: 1408-1411.

Dos Reis T.F., Menino J.F., Bom Vl.P., Brown N.A., Colabardini A.C., SAVOldi M., GoldMAN M.H., RODRIGUES F. and GOLDMAN G.H. 2013. Identification of Glucose Transporters in Aspergillus nidulans. PLoS ONE 8(11): e81412. doi:10.1371/journal.pone.0081412.

DREESENS L.L., LEE C.K. and CARY S.C. 2014. The distribution and identity of edaphic fungi in the McMurdo Dry Valleys. Biology 3: 466-483. 
ELLIS-EVANS J.C. and WYNN-WILLIAMS D.D. 1985. The interaction of soil and lake microflora at Signy Island. In: W.R. Siegfried, P.R. Condy and R.M. Laws (eds), Antarctic Nutrient Cyclesand Food Webs. Springer-Verlag, Berlin: 662-668.

Feller G., NarinX E., Arpigny J.L., Aittaleb M., Baise E., Genicot S. and Gerday C. 2006. Enzymes from psychrophilic organisms. FEMS Microbiology Reviews 18: 189-202.

FENICE M. 2016. The psychrotolerant Antarctic fungus Lecanicillium muscarium CCFEE 5003: a powerful producer of cold-tolerant chitinolytic enzymes. Molecules 21: 447.

Fenice M., Barghini P., Selbmann L. and Federici F. 2012. Combined effects of agitation and aeration on the chitinolytic enzymes production by the Antarctic fungus Lecanicillium muscarium CCFEE 5003. Microbial Cell Factories 11: 12.

Feofilova E.P., Tereshina V.M., KhoKhlova N.S. and Memorskaya A.S. 2000. Different mechanisms of the biochemical adaptation of mycelial fungi to temperature stress: Changes in the cytosol carbohydrate composition. Microbiology 69: 504-508.

FRIDOVICH I. 1998. Oxygen toxicity a radical explanation. Journal of Experimental Biology 201: 1203-1209.

FRISVAD J.C. 2008. Fungi in cold ecosystems. In: R. Margesin,F. Schinner, J.C. Marx and C. Gerday (eds), Psychrophiles: From Biodiversity to Biotechnology. Springer-Verlag, Berlin Heidelberg: 137-156.

FUKUNAGA N. and RUSSELL N.J. 1990. Membrane lipid composition and glucose uptake in two psychrotolerant bacteria from Antarctica. Journal of General Microbiology 136: 1669-1673.

Gocheva Y., Krumova E., Slokoska L., Miteva J. and Angelova M. 2006. Cell response of Antarctic and temperate strains of Penicillium spp. to different growth temperature. Mycological Research 110: 1347-1354.

Gocheva Y., Tosi S., Krumova E., Slokoska L., Miteva J., Vassilev S. and Angelova M. 2009. Temperature downshift induces antioxidant response in fungi isolated from Antarctica. Extremophiles 13: 273-281.

Gonçalves V.N., CAmpos L.S., Melo I.S., Pellizari V.H., Rosa CA. and Rosa L.H. 2013. Penicillium solitum: A mesophilic, psychrotolerant fungus present in marine sediments from Antarctica. Polar Biology 36: 1823-1831.

GonÇalves V.N., VAZ A.B., Rosa C.A. and Rosa L.H. 2012. Diversity and distribution of fungal communities in lakes of Antarctica. FEMS Microbiology Ecology 82: 459-71.

IORDACHESCU M. and IMAI R. 2011. Trehalose and abiotic stress in biological systems. In: A.K. Shanker and B. Venkateswarlu (eds), Abiotic Stress in Plants - Mechanisms and Adaptations. InTech, Croatia: 215-234.

KANWAL S., SAHARAN R.K., MAHMOOD A. and SHARMA S.C. 2011. Effect of reserve carbohydrates on oxidative stress in yeast Saccharomyces cerevisiae Y6210. Current Research Journal of Biological Sciences 3: 633-636.

Kostadinova N., Krumova E., Stefanova Ts., DishliJsKa V. and Angelova M. 2012. Transient cold shock induces oxidative stress events in Antarctic fungi. In: V. Lushchak (ed.), Oxidative Stress. Book 1. InTech, Rijeca, Croatia: 75-99.

Kostadinova N., Krumova E., Tosi S., Pashova S. and Angelova M. 2009. Isolation and identification of filamentous fungi from island Livingston, Antarctica. Biotechnology \& Biotechnological Equipment 23/SE: 267-270.

Kostadinova N., Vassilev S., Spasova B. and Angelova M. 2011. Cold stress in Antarctic fungi targets enzymes of the glycolytic pathway and tricarboxylic acid cycle. Biotechnology \& Biotechnological Equipment 25: 50-57.

Li Q., ABRASHEV R., HARVEY L.M. and MCNEIL B. 2008. Oxidative stress-associated impairment of glucose and ammonia metabolism in the filamentous fungus, Aspergillus niger B1-D. Mycological Research 112 (Pt 9): 1049-1055. 
LOWRy O.H., Rosenbrough H.J., FAAR A.L. and RANDALL R.J. 1951. Protein measurement with the Folin phenol reagent. The Journal of Biological Chemistry 193: 265-275.

LU P., SANG W.G. and MA K.P. 2008. Differential responses of the activities of antioxidant enzymes to thermal stresses between two invasive eupatorium species in China. Journal of Integrative Plant Biology 50: 393-401.

MARGESIN R. 2009. Effect of temperature on growth parameters of psychrophilic bacteria and yeasts. Extremophiles 13: 257-262.

Matsumoto M. and Hsiang T. 2016. Snow Molds. The Battle Under Snow Between Fungal Pathogens and Their Plant Hosts. Springer, Science+Business Media Singapore: 136 pp.

NONZOM S. and SumBaLI G. 2014. Fate of mitosporic soil fungi in cold deserts: A review American International Journal of Research in Formal, Applied \& Natural Sciences 9: 01-09.

NEWSHAM K.K., UPSON R. and READ D.J. 2009. Mycorrhizas and dark septate root endophytes in polar regions. Fungal Ecology 2: 10-20.

NIMSE S.B. and PAL D. 2015. Free radicals, natural antioxidants, and their reaction mechanisms RSC Advances 5: 27986-28006.

Onofri S., Barreca D., Selbmann L., Isola D., Rabbow E., Horneck G., De Vera J.P.P., HatTON J. and ZUCCONI L. 2008. Resistance of Antarctic black fungi and cryptoendolithic communities to simulated space and Martian conditions. Studies in Mycology 61: 99-109.

Onofri S., De Vera J.P., Zucconi L., Selbmann L., Scalzi G., Venkateswaran Ku., Rabbow E., DE LA TORRE R. and HoRNECK G. 2015. Survival of Antarctic cryptoendolithic fungi in simulated martian conditions on board the international space station. Astrobiology 15: 1052-1059.

Onofri S., Selbmann L., Zucconi L., Tosi S. and De Hoog G.S. 2005. The Mycota of continental Antarctica. Terra Antarctica Reports 11: 37-42.

Park C.H., Kim K.M., ElvebaKK A., Kim O.S., JeOng G. and Hong S.G. 2015. Algal and fungal diversity in Antarctic lichens. The Journal of Eukaryotic Microbiology 62: 196-205.

PARROU J.L., TESTE M.A. and FrANCOIS J. 1997. Effects of various types of stress on the metabolism of reserve carbohydrates in Saccharomyces cerevisiae: genetic evidence for a stress-induced recycling of glycogen and trehalose. Microbiology 143: 1891-1900.

RaO S., Chan Y., LACAP D.C., HYDE K.D., PoinTing S.B. and FARRELl R.L. 2012. Low-diversity fungal assemblage in an Antarctic Dry Valleys soil. Polar Biology 35: 567-574.

Ruisi S., Barreca D., Selbmann L., Zucconi L. and OnOFri S. 2007. Fungi in Antarctica. Reviews in Environmental Science and Bio/Technology 6: 127-141.

RUSSELL N.J. 2006. Antarctic microorganisms: coming in from the cold. Culture (Oxoid) 27: 1-4.

SABri A., JacQues P., WeEkers F., Bare G., Hiligsmann S., Moussaif M. and ThONART P. 2000. Effect of temperature on growth of psychrophilic and psychrotrophic members of Rhodotorula aurantiaca. Applied Biochemistry and Biotechnology 84-86: 391-399.

Schade B., JANSEN G., Whiteway M., EnTIAN K.D. and Thomas D.Y. 2004. Cold adaptation in budding yeast. Molecular Biology of the Cell 15: 5492-550.

Selbman L., De Hoog G.S., Zucconi L., Isola D. and OnOFRI S. 2014. Black yeast in cold habitats. In: P. Buzzini and R. Margesin (eds), Cold-adapted Yeasts: Biodiversity, Adaptation Strategies and Biotechnological Significance. Springer, Heidelberg, NY, London: 173-192.

Sharma P., Jha A.B., Dubey R.S. and PessaraKLi M. 2012. Reactive oxygen species, oxidative damage, and antioxidative defense mechanism in plants under stressful conditions. Journal of Botany 2012, Article ID 217037: 1-26.

Shilova N.K., MatYASHOVA R.N. and IlCHENKO A.P. 1989. The effect of aeration on the activity of alcohol oxidase and enzymes utilising hydrogen peroxide in the course of Candida maltosa growth on paraffin. Microbiologiya 58:430-435 (in Russian). 
Silvi S., Barghini P., Aquilanti A., Juraez-Jimenez B. and Fenice M. 2013. Physiologic and metabolic characterization of a new marine isolate (BM39) of Pantoea sp. producing high levels of exopolysaccharide. Microbial Cell Factories 12: 10.

Sofo A., SCOPA A., NuZZACI M. and VITTI A. 2015. Ascorbate peroxidase and catalase activities and their genetic regulation in plants subjected to drought and salinity stresses. International Journal of Molecular Sciences 16: 13561-13578.

Somogy M. 1952. Notes on sugar determination. The Journal of Biological Chemistry 195: 19-23.

STERFLINGER K. 2006. Black yeast and meristematic fungi: ecology, diversity and identification. In: G. Péter and C. Rosa (eds), The Yeast Handbook. Biodiversity and Ecophysiology of Yeasts. Springer, Berlin, Heidelberg: 501-514.

TsuJI M. 2016. Cold-stress responses in the Antarctic basidiomycetous yeast Mrakia blollopis. Royal Society Open Science 3(7): 160106.

WANG M., Jiang X., Wu W., Hao Y., Su Y., CAi L., XIAng M. and LIU X. 2015. Psychrophilic fungi from the world's roof. Persoonia: Molecular Phylogeny and Evolution of Fungi 34: 100-112.

WeINSTEIN R.N., MONTIEL P.O. and JohnSTONE K. 2000. Influence of growth temperature on lipid and soluble carbohydrate synthesis by fungi isolated from fellfield soil in the maritime Antarctic. Mycologia 92: 222-229.

Willekens H., Chamnongpol S., Davey M., Schraudner M., LANGebartels C., Van MonTAGU M., INZÉ D. and VAN CAMP W. 1997. Catalase is a sink for $\mathrm{H}_{2} \mathrm{O}_{2}$ and is indispensable for stress defense in C3 plants. European Molecular Biology Organisation 16: 4806-4816.

Zhang L., Onda K., Imai R., FuKUda R., Horiuchi H. and OHTA A. 2003. Growth temperature downshift induces antioxidant response in Saccharomyces cerevisiae. Biochemical and Biophysical Research Communications 307: 308-314.

Zhang T., Wei X.L., Zhang Y.Q., LiU H.Y. and YU L.Y. 2015. Diversity and distribution of lichenassociated fungi in the Ny-Ålesund Region (Svalbard, High Arctic) as revealed by 454 pyrosequencing. Scientific Reports 5: 14850.

Received 24 November 2016

Accepted 8 May 2017 